\title{
Vincent Wright
}

\section{Las privatizaciones en Gran Bretaña (*)}

SUMARIO: 1. LA DIMENSION DE LA PRIVATIZACION. 2. LAS RAZONES DE LA PRIVATIZACION. 3. EXTENSION Y LIMITES DE LA PRIVATIZACION. 4. PRIVATIZACION: OBSTACULOS Y RESTRICCIONES. 5. PRIVATIZACION: PROBLEMAS, CONTRADICCIONES Y PARADOJAS. 6. EL REPLIEGUE DE ESTADO: HIBRIDOS Y QUANGOS. 7. CONSIDERACIONES FINALES.

\section{LA DIMENSION DE LA PRIVATIZACION}

Desde 1979, la privatización en el Reino Unido ha adoptado muchas formas (1); se trata de un término muy amplio que cubre muchas políticas distintas vinculadas por la forma de su utilización para refor-

(*) El INAP y la Redacción de DOCUMENTACION ADMinISTRATTVA quieren dejar constancia de su agradecimiento tanto al autor como a la Rivista Trimestrale di Diritto Publico y su editor por la autorización concedida para la traducción y publicación de este trabajo, a partir del texto publicado en el número 1 del año 1988 de dicha Revista.

(1) La literatura sobre la privatización es una de las pocas industrias en desarrollo del Reino Unido. Son de especial utilidad: J. KAY et at., Privatization and Regulation: the U.K. experiencie, Oxford, 1986; M. BeEsley y S. LITTLEChILD, «Privatization: Principles and Priorities», en Lloyd's Bank Review, núm. 149, julio, 1983, pp. 1-20; S. BRITTAN, «The politics and Economic of Privatization», en Political Quarterly, vol. 55 (2), abril-junio 1984, pp. 109-128); P. CURWEN, Public Enterprise: A modern aproach, Nrighton, 1986, pp. 157-285; P. DUNLEAVY, «Explaining the Privatization Boom: Public Choice versus Radical Approachesm, en Public Administration, vol. 64, Spring, 1986, pp. 13-14; D. HEALD, Public Expedinture: its Defence and Reform, Oxford, 1983; D. HEALD, «Privatization: analysing its appeal and limitation», en Fiscal Studies, $\mathrm{r}$ (1), 1984, pp. 34-46; D. HEALD, «Will the Privatization of Public Enterprises solve the problem of control?», en Public Administration, vol. 63, Spring, 1985, pp. 7-22; S. HASTINGS, H. HASTINGS y H. LEVIE, Privatization?, Nottingham, 1983; P. JACKSON, Implementing Gobernment Policy Initiatives: the Thabcher Administration, 1979-1983, Londres, Instituto de Administración Pública, 1985; J. A. KAY y Z. A. SILBERSTON, «The new industrial policy privatization and competition», en Midland Bank Review, Spring, 1984, pp. 8-16; D. STEEL y D. HEALD (eds.), Privatizing Public Enterprise: options and dilemmas, Londres, 1984; D. WHTTFIELD, Making it Public, Londres, 1983; S. S. Young, «The Nature of Privatization in Britain, 1979-1985», en West European Politics, 
zar el mercado a expensas del Estado (2). A los efectos de este documento se considera que comprende un amplio espectro de políticas orientadas a reducir el campo de acción del sector público, limitar sus funciones y debilitar su influencia. En resumen, forma parte de una estrategia más amplia para alterar los límites de los sectores público y privado.

Existen muchas formas de clasificar las diferentes manifestaciones de la privatización: por intención, por impacto, sectorialmente...; por tanto, la clasificación que sigue es una de las muchas posibles:

- La abolición o fuerte reducción de los servicios públicos, presumiendo que serán sustituidos espontáneamente por la iniciativa privada (por ejemplo, el drástico corte del servicio escolar de comidas).

- La reducción de los recursos financieros a determinados organismos sostenidos con fondos públicos con la intención de inducirlos a procurarse financiación privada: ésta es la política claramente defendida para las artes (el Consejo de las Artes), las universidades (el Comité de Subvenciones Universitarias), determinadas funciones medioambientales (El Consejo de Conservación de la Naturaleza) y ciertas formas de ayuda regional (las Agencias para el Desarrollo de Gales y Escocia).

- El incremento de la contribución financiera de los consumidores y usuarios de bienes públicos (pago de recetas, gafas, reparaciones municipales, comidas escolares, entradas a galerías de arte y museos).

- El estímulo de la participación del sector privado en proyectos de inversiones públicas, como los programas de renovación urbana o de rehabilitación de edificios en Inglaterra. Así, la renovación masiva de los muelles de Londres se confió a la London Docklands Corporation, creada en 1981, y compuesta por representantes centrales y locales (que actualmente la boicotean) y por grandes empresas financieras.

- La promoción de empresas mixtas: de aquí los llamados Planes Phoenix, que suponían colaboraciones de empresas del acero privadas con la British Steel.

- La transferencia al sector privado de determinadas responsabilidades públicas; así se ha reforzado el papel de los establecimientos privados en el cuidado de los ancianos y disminuidos mentales y físicos.

vol. 9 (2), abril 1986, pp. 235-252. Sobre la privatización del servicio Welfare véase J. LE GRAND y RoBinson (eds.), Privatization and the Welfare State, Londres, 1984. Por un buen sumario véase, J. LE GRAND, «Privatization and the Social Services», en J. GriffiTHS (ed.), Socialism in a Cold Climate, Londres, 1983, pp. 65-80. Véanse también M. OHIGgINS, «Privatization and Social Security», en Political Quarterly, vol. 55 (2), abril-junio, 1984, pp. 129-139; G. YARROW, «Privatization in Theory and Practice», en Economic Policy, abril, 1986, pp. 325-327; C. veljanovski, Selling the State: Privatization in Britain, Londres, 1987.

(2) D. Heald, Public Expenditure..., cit., p. 298. 
- El estímulo de la financiación privada en la ejecución y desarrollo de obras públicas: una política muy favorecida por la derecha. Estos son los casos del puente de cuatro carriles sobre el Támesis por Trafalgar House y del túnel del Canal de la Mancha.

- La introducción en el sector público de las técnicas de gestión y eficacia propias del sector privado.

- Promover la competencia del sector privado con el público a través de una política de liberalización. Se han relajado algo los monopolios legales o el sistema de licencias en muchas áreas: no se permite a las empresas privadas competir con Correos en ciertos servicios (por ejemplo, correo expreso y venta de sellos), con British Gas (antes de la desnacionalización), en suministros a industriales [Oil and Gas (Enterprise) Act, 1982], con British Airways en ciertas rutas nacionales (Civil Aviation Act, 198...) y con British Telecom (antes de la desnacionalización), para ciertos servicios telefónicos (Britisb Telecomunications Act, 1981). No obstante, el área más afectada ha sido el transporte por carretera que se ha liberalizado progresivamente.

- La concesión de servicios públicos a agentes privados. Se ha estimulado u obligado a departamentos administrativos centrales, entes locales, el Servicio Nacional de Salud e industrias nacionalizadas a someter a licitación ciertos servicios.

- Pero la venta de activos públicos a sujetos privados es la dimensión más patente y llamativa del movimiento privatizador, que proporciona el enfoque de este documento.

Este aspecto de la privatización ha adoptado varias formas:

a) La venta forzosa de activos rentables pertenecientes a industrias nacionalizadas. Así British Rail tuvo que vender Sealink (el servicio del cruce del canal y su cadena hotelera) y British Airways su Centro de Formación Aérea y 47 aviones ligeros por 5,3 millones de libras, así como la rentable filial Internacional Aeradio a Standard Telephone and Cables. Se obligó a British Gas a deshacerse de Wytch Farm Oilfield, que valía 500 millones de libras, y se vendieron también 1.880 instalaciones de gas y energía eléctrica pertenecientes a industrias nacionalizadas. British Leyland dejó Jaguar Cars y el Consejo Nacional de Electricidad ha vendido sus acciones de Ferranti, Icc, Fairey y otras 24 empresas.

b) La venta de casas municipales a sus inquilinos con el 50 por 100 de descuento (the 1980 Housing Act), una de las medidas privatizadoras más populares, pero también más controvertidas.

c) La venta de acciones en empresas y otros activos en que el Estado tenía participación, no necesariamente mayoritaria. Los ejemplos más relevantes han sido las ventas de acciones de British Petroleum, que supusieron 276 millones de libras en el año 1979-1980, y 542 mi- 
llones en el de 1983-84; el resto de la participación estatal en BP (un 31,7 por 100) se vendió en noviembre de 1987. El Estado vendió también su participación minoritaria en la British Sugar Corporation.

d) La desnacionalización de empresas o de grupos de empresas, que ha sido muy amplia.

El programa privatizador ha sido, pues, de gran alcance. Ha alcanzado a la Administración local, a las industrias nacionalizadas, al Servicio Nacional de Salud, a los departamentos centrales y quangos (*), y a la mayor parte de las áreas sectoriales: industria, transporte, vivienda y educación, se han visto afectadas.

Dicho programa privatizador ha seguido líneas distintas, pero interrelacionadas (3):

- Las que intentan a corto plazo vencer el equilibrio actual hacia el sector privado, reduciendo el papel y dimensiones del sector público, y estimulando al privado para que ofrezca bienes y servicios antes pertenecientes al sector público.

- Las de impacto a largo plazo, a través de la creación de un contexto adecuado para la expansión del sector privado.

- Las orientadas a un uso mayor de los recursos del sector privado en el desarrollo de las funciones públicas: se moviliza el sector privado para atender al público.

- Las que se proponen introducir personal, experiencias y métodos de funcionamiento del sector privado en el público.

Pero antes de examinar el impacto del programa privatizador conviene recordar brevemente las razones del gobierno conservador para justificarlo.

\section{LAS RAZONES DE LA PRIVATIZACION}

No disponemos de una explicación sistemática sobre los motivos de la privatización: por ello es preciso deducirlos de los discursos ministeriales, de los manifiestos electorales de 1979, 1983 y 1987, de los debates parlamentarios, de los documentos del Partido Conservador y de las leyes correspondientes. Una primera serie de motivos a los que hay que aludir es de carácter ideológico. Así la privatización es una respuesta al «butskellismo» o al «macwilsonismo» -el consenso socialdemócrata y semicolectivista de la posguerra-. También es el enfoque de una campaña de desmantelamiento de partes del Estado -el

(*) Quasi autonomons non governamental organisations: entes semipúblicos cuya financiación y nombramiento de directivos compete al Gobierno (N. del T.).

(3) G. YounG, op. cit., pp. 236-237. 
Estado inhibidor, omnipresente y embrutecedor que erosiona la responsabilidad personal y socava la iniciativa privada-. El papel del Estado es crear el medio adecuado para los operadores individuales con incentivos fiscales, la supresión de restricciones, la flexibilización de las normas de planificación y de las rigideces del mercado de trabajo. La autonomía y la autodependencia son las virtudes cardinales del catecismo thatcherista. Un segundo puntal ideológico de la privatización es la convicción de que los servicios e industrias públicas limitan las posibilidades de opción del consumidor debido a su posición monopolística. Como dijo en 1981 Geoffrey Howe, entonces Ministro de Hacienda, «el consumidor es soberano en el sector privado. En el público, le destronan la subvención y el monopolio». Además, la titularidad pública priva a los individuos de libertad económica al obligarles a detentar «accionariados implicados» que quizá rechazarían, si pudieran. El thatcherismo rechaza el colectivismo basado en la elección social, en favor de la empresa privada arraigada en la elección individual (para la sanidad, educación y seguridad social). La tercera línea ideológica es la necesidad de constituir una «democracia de la propiedad»: $\mathrm{Ni}$ cholas RIDLEY, uno de los grandes campeones privatizadores del gobierno, ha afirmado que ello produciría la auténtica «propiedad pública», o sea, «la propiedad de la gente» (4).

De ahí la venta a los inquilinos de viviendas municipales y, también, la venta de acciones de industrias desnacionalizadas a un público lo más amplio posible y, sobre todo, a los trabajadores de esas industrias.

La segunda serie es la de los motivos «económicos». En primer lugat, se ha visto la privatización como un medio de impulsar la liberalización. Muchos de los monopolios estatales no son monopolios naturales (incluso aunque en el gas y en la energía eléctrica pueda haber un monopolio natural de distribución a través de la red nacional no alcanza a la producción), por lo que, una vez desmontados, mejorarán posibilidades de competir. Se ha argüido que para los servicios que tienen pérdidas de inspiración política y social les es más eficaz proporcionar subvenciones específicas a consumidores necesitados. Un segundo argumento económico ha consistido en afirmar que los servicios y la producción del sector público son intrínsecamente menos eficaces que los del privado (5). Lo son porque no son sensibles a los aires tonificantes de las fuerzas del mercado, y están protegidos por la obligación del Estado de pagar la factura de sus pérdidas. Se dice que las empresas públicas están al margen de los mercados de capitales y pro-

(4) Cfr. D. STELl y D. HeAld, op. cit., p. 72.

(5) Uno de los principales argumentos de R. S. PRYKe, The Nacionalised Industries: Policies and Performances, Londres, 1981. 
ductos. No se enfrentan con amenazas de quiebra o absorción y no han de responder ante accionistas privados. Además, privados de la posibilidad de beneficio económico directo, sus directivos se «garantizarán beneficios en forma de status, seguridad y comodidades institucionales» (6). A ello se añade que cuando están motivados por la necesidad de mayor eficacia y beneficios, les frustran los gobiernos con sus objetivos macroeconómicos y de redistribución de la renta. Existe en el fondo en los círculos thatcherianos una profunda desconfianza hacia los programas político-administrativos que sustituyen al mercado como mecanismo de asignación de recursos. Se prefiere a los empresarios desinhibidos y orientados al mercado y al beneficio antes que a burócratas «inflapresupuestos» y políticos «busca-votos» (7).

Vinculada a la motivación económica de la privatización se encuentra la cuestión «directiva». Se estima que la privatización es un medio de quebrantar los vastos imperios del sector público —azotados por luchas intestinas de barones y protegidos por la ley y las ayudas públicas- La privatización debería facilitar la segregación de los elementos «incoherentes» y la racionalización de las estructuras directivas de estos mal utilizados instrumentos de la política pública (8). Además permitiría a los Ministros liberarse de unas relaciones totalmente absorbentes e inútiles con el sector público, relaciones en las que el Ministro o abraza la causa de las industrias que se supone debe controlar, o interfiere demasiado. La sencilla concepción de Morrison sobre la relación demuestra aquí ser totalmente inoperante. Continuamente se producen enfrentamientos entre los Ministros y los dirigentes del sector público por los topes salariales, los planes de inversiones, las necesidades de endeudamientos, los proyectos de reestructuración y por el derecho de recaudar capital sin control del Tesoro. La relación se ha vuelto un caos (9), lleno de «ambigüedad, indecisión y vacilación» (10). Por tanto, la privatización garantizaría autonomía e incentivos.

La cuarta panoplia de razones para la privatización es la «política». Se ha dicho que es popular entre los fieles del Partido Conservador, y es la forma de calmar a su ala de extrema derecha, que está descontenta ante la incapacidad del gobierno para transformar radicalmente la economía. Aún más, se dice que la privatización debe considerarse como parte de la lucha sostenida del gobierno contra los bastiones del

(6) S. BRITTAN, op. cit.

(7) P. DUNLEAVY, op. cit., p. 16.

(8) D. Heald, Will the Privatization..., cit., p. 10.

(9) S. R. M. WILKS, U. K. Industrial Policy: Instruments, Institutions and the State, ECPR Workshop Paper, Aarhus, 1982 (no publicado).

(10) J. L. METCALFE, «Gobernment-Industry Relations», en Post-Keynesian Economy, Londres, 1980 (no publicado). 
Partido Laborista (Administración local, vivienda pública) y del movimiento sindical (Administración local e industrias del sector público) (11). También ha sido un medio de controlar los aumentos salariales «excesivos» conquistados por los poderosos sindicatos ante unos dirigentes de empresas públicas que siempre pueden recurrir al Tesoro para financiar déficits.

Finalmente, se han aducido razones «financieras». La primera está relacionada con la curiosa actitud del gobierno con la necesidad de endeudamiento del sector público (NESP), que está decidido a reducir (ahora sólo a moderarla) (12). Se discute qué debería incluirse en la NESP, pero lo que está claro es que en el caso de las empresas públicas vendidas totalmente $\longrightarrow$ un paquete importante de sus accioneslos programas de inversión de capital han sido cargados en las cuentas del sector público. Así, al venderse activos rentables, se mejora la apariencia de esas cuentas. Es otro ejemplo de cómo los gobiernos - de todo sesgo- tratan las cifras incómodas. La segunda razón financiera a menudo citada es que la privatización, a través de la desnacionalización, proporciona el acceso directo de las empresas implicadas a los mercados de capitales internacionales (aunque no queda claro por qué se encuentran privadas de tal derecho las empresas nacionalizadas...). En tercer lugar, se afirma que la venta de activos reduce el riesgo comercial del gobierno ante las incertidumbres de la recesión. También así se evitarían las tremendamente caras operaciones de rescate de empresas públicas (como BSC, Rolls Royce, British Leyland, British Sirways, International Computers). Finalmente, y aquí nos topamos con los principales motivos, el mayor coste de los bienes públicos, la reducción de pérdidas, el aumento del gasto del consumidor de bienes públicos, la reducción de préstamos para cubrir pérdidas, la atracción del sector privado en la financiación de bienes y servicios públicos y la venta de activos estatales permiten al gobierno perseguir otros objetivos, como la reducción de impuestos sobre personas y sociedades y la financiación del gasto público, que sigue siendo alto.

Así pues, en cierto modo, la privatización se justifica más como respuesta a los fracasos del sector público que por sus ventajas intrínsecas.

(11) D. WHITFIELD, op. cit., Pp. 23-24; D. HEALD, Will the Privatization, cit., p. 11.

(12) J. R. ShACKLETon, «U. K. Privatization» y «U. S. Deregulation», en Politics, vol. 5 (2), octubre 1985, pp. 14-15; R. BUCKLAND y E. W. DAvIS, «Privatization Techniques and PSBR», en Fiscal Studies, 5 (3), 1984, pp. 44-53; A. PEACOCK, «Privatization in Perspective», en Three Banks Review, 144, 1984, pp. 3-26. 


\section{EXTENSION Y LIMITES DE LA PRIVATIZACION}

El programa privatizador del gobierno Thatcher ha tenido sus éxitos; se han recaudado grandes sumas (17.500 millones de libras entre 1979 y 1987; 5.600 millones de libras sólo de British Gas en 1986); durante el mismo período se han privatizado total o parcialmente 16 empresas de propiedad mayoritariamente pública que daban empleo a 650.000 personas y suponían el 40 por 100 del sector estatal; el número de accionistas ha crecido de manera impresionante (a unos $8 \mathrm{mi}$ llones y medio) como resultado de las ventas de activos públicos; se han vendido 850.000 viviendas municipales y recortado las subvenciones al sector de la vivienda pública; se ha desnacionalizado y liberalizado el transporte por carretera. Pero es preciso analizar estos datos con cierta cautela. Por ejemplo, el Estado conserva una presencia masiva y «distorsionadora» en el mercado de la vivienda pública y privada, motivo de cierta irritación para la derecha (13).

Por otra parte, no obstante lo llamativas que han sido, las ventas de activos públicos no deben ocultar la limitada incidencia, en términos globales, de estas operaciones, inclusive en el sector industrial. Aun después de la venta de British Gas y British Airways, el sector público sigue teniendo gran envergadura [energía eléctrica, agua (a la espera de ser privatizadas), carbón, acero, ferrocarriles, astilleros, armadores, sectores de la industria automovilística]. Además, el Estado ha conservado importantes participaciones en grandes empresas desnacionalizadas (British Gas, British Telecom, Britoil, British Aerospace, Cable and Wireless), y en algunas empresas desnacionalizadas el gobierno ha creado un tipo especial de participación con el fin de dar al Secretario de Estado poder de veto en determinadas circunstancias.

Es más, el Estado sigue interviniendo masivamente en la economía, regula sus límites y determina el contexto de actuación de las empresas públicas y privadas:

- Influyendo en la propiedad (han sido muy reveladores sus constantes intervenciones en la conflictiva división de helicópteros de Westland y su papel en los acalorados debates sobre la venta de partes de British Leyland).

- A través de sus políticas de educación y formación profesional (progresivamente centralizadas).

- Mediante su política de competencia y fusiones.

- A través de su posición general en materia fiscal.

(13) P. Minford, P. Ashton y M. Peel, «Housing Reform to create, jobs», en Economic Affair, vol. 6 (3), febrero-marzo 1986, pp. 32.34. 
- Por medio de su política de relaciones industriales.

- Mediante su presencia en la investigación y el desarrollo.

- Mediante su política salarial (aunque finja no tenerla).

- A través de su política de asistencia pública (que sigue siendo sutil y firmemente nacionalista).

- Por medio de su política comercial (que, para desesperación de los juristas de la derecha, aún es intervencionista, a través de las tarifas, cuotas, prohibiciones, restricciones e importadores, garantías de préstamos y créditos, subvenciones a adquirentes extranjeros, campañas de promoción de exportaciones, acuerdos «voluntarios» restrictivos de exportaciones).

- Por su política energética.

- Por su política de protección medioambiental.

- Por su aproximación a las regulaciones de planificación.

- Mediante su legislación de protección al consumidor (que ha aumentado desde 1979).

- A través de su política de subvenciones directas e indirectas, en forma de concesiones, préstamos, tierra barata, exenciones fiscales, servicios y asesoramiento a industrias en dificultades (la industria privada del estaño recibió 25 millones de libras en 1986), a regiones deprimidas, a ciudades del interior en estado lamentable, y a industrias florecientes, como las de microprocesadores, tecnología de la información, robótica y biotecnología. Como a veces es imposible determinar en qué consiste exactamente una subvención, se hace difícil calcular el importe total de las subvenciones a la industria británica. No obstante, todos los indicios sugieren que siguen siendo masivas, aunque últimamente el Estado ha sido más selectivo en su orientación.

En pocas palabras, el Estado sigue siendo suministrador, regulador, empresario, adquirente y árbitro, en el ámbito económico e industrial, imponiendo restricciones a algunos operadores y proporcionando redes de seguridad a otros.

Una de las muchas paradojas del gobierno Thatcher es que su ética de «valor por dinero» invita ineludiblemente a un intervencionismo estatal muy minucioso. Ha sido el caso de las relaciones del gobierno con: a) la Administración local, ya que se ha producido una intromisión del poder central sin precedentes en los asuntos de los entes locales; b) el Servicio Nacional de Salud; c) los diversos quangos que distribuyen asistencia sectorial y regional, y $d$ ) el sector universitario, respecto del que las Administraciones anteriores habían seguido una estrategia de «manos fuera». 


\section{PRIVATIZACION: OBSTACULOS Y RESTRICCIONES}

En su intento de alterar los límites entre lo público y lo privado, el gobierno ha tropezado con una serie de obstáculos y límites. Ello ha ocasionado la lentitud en algunos aspectos del programa privatizador, la limitación de los objetivos en otros e, incluso, la renuncia a algunos.

En primer lugar, se han planteado límites prácticos o técnicos. Por ejemplo, la calamitosa situación de muchas empresas públicas ha impedido la desnacionalización. Ha sido necesario recapitalizarlas, reestructurarlas y modernizarlas (con grandes sumas de dinero público) para hacerlas atractivas a los inversores privados. Los problemas técnicos que plantearon las desnacionalizaciones del agua y la energía eléctrica fueron tan grandes que seguían en el sector público en las elecciones de 1987.

En segundo lugar, están los límites legales: la larga y costosa batalla ante los tribunales americanos sobre el papel de British Airways en la desaparición de las aerolíneas de Freddy Laker; el prolongado litigio por la propiedad del Trustess Saving Bank, vendida al final de 1986; la compleja batalla por la privatización de la British National Oil Corporation, que involucró a equipos de asesores legales y financieros del Departamento de Energía y las dos sucesoras de la sociedad original (BNOC y Britoil).

El tercer límite ha sido de naturaleza cultural y electoral. Diversos aspectos del programa privatizador han demostrado su atractivo. La venta de viviendas municipales ha sido tan popular que el Partido Laborista, inicialmente hostil a ella, hubo de cambiar su postura. Tampoco el programa desnacionalizador ha planteado ningún problema importante: a menudo, la imagen de las industrias nacionalizadas es tributaria de las gigantescas organizaciones burocráticas, cargadas de personal, pérdidas e ineficacia de las vías férreas, el acero y el carbón. El gobierno también consiguió apoyo político para la desnacionalización al garantizar que las acciones iban a ser adquiridas a bajo precio por pequeños inversores y trabajadores. Sin embargo, conviene notar que aunque los votantes tienden a ser más hostiles a la nacionalización que a la privatización, las propuestas privatizadoras del gobierno «al afectar a servicios básicos, como el gas y el agua, las dudas surgen» (14).

Toda propuesta que afecte radicalmente la sanidad, la seguridad social y la educación ha concitado una hostilidad atávica; a diferencia de la vivienda pública, se perciben como partes fundamentales del patri-

(14) A. KING, «Who'll win the 1987 election?», en The World in 1987, Economist Intelligence Unit, 1986, p. 15. 
monio del Estado del Bienestar (15). Los sondeos de opinión han demostrado continuamente la preferencia de una gran mayoría del electorado por la conservación o mejora de los servicios públicos frente a las reducciones fiscales (16); el consenso democrático posbélico, mantenido por sucesivos gobiernos hasta 1979 ha arraigado en el campo electoral británico. Resulta igualmente claro que un sector importante del Partido Conservador ha apoyado, por distintos motivos, el aumento del gasto público y se ha mostrado escéptico sobre las reducciones de impuestos: algunos estaban realmente preocupados por la división social de estas políticas; otros, por el impacto del creciente consumo (y de las importaciones) como resultado de las reducciones fiscales; otros, por la amenaza a los intereses de sus electores de clase media, y el resto, por la impopularidad generalizada de la retórica gubernamental anti-sector público. Es significativo el que las campañas electorales de 1979, 1983 y 1987 provocaran que el liderazgo thatcherista hubiera de enfatizar su compromiso con la sanidad pública, la educación y la seguridad social. Más cínicamente podría decirse que la privatización de los activos públicos ha supuesto a los accionistas pérdidas (a causa del bajo precio político de venta), mientras la privatización de los servicios públicos implica mayores costes para los electores.

El cuarto grupo de límites al plan thatcherista de reducción del sector público consiste en la incapacidad o el desinterés del sector privado para responder a las oportunidades que se le ofrecen. Ello ha sido generalmente consecuencia de la inadecuación de los recursos o de la renuencia a implicarse en programas a largo plazo y de alto riesgo. Resulta revelador que el proyecto de financiación privada del túnel del Canal — «el proyecto de ingeniería civil más atrayente del siglo»- apenas pudo reunir un grupo de inversores internacionales para la primera fase del proyecto ( $y$ tras gran presión entre bastidores del gobierno Thatcher). De modo semejante, las empresas aseguradoras privadas se mostraban muy renuentes a hacerse cargo del sistema de pensiones privadas subsiguiente a la supresión del sistema de pensiones estatal. La esperanza gubernamental de que la contracción del sector público fuera compensada por el privado demostró estar muy lejos de la realidad. El último límite al «repliegue del Estado» ha sido la eficacia de algunos grupos estratégicamente situados para oponerse a la mutilación del sector público. Dentro de tales grupos no se encuentran los sindicatos nacionales, cada vez más desmoralizados y desorientados después del año 1979 [el gobierno se ha enfrentado - y ha derrotado- a los sin-

(15) G. BOYNE, «The Privatization of Public Housing», en Political Quarterly, 55 (2), abriljunio, 1984, pp. 182-184.

(16) A. KING, op. cit., p. 15; R. Rose, "Getting Big in Three Economesi: the resources of the official, unoficial and domestic economies», en J. E. LANE, State and Market: The Politics of the Public and the Private, Londres, 1985, pp. 114-115. 
dicatos en las empresas nacionalizadas (ferrocarriles, acero y, por supuesto, carbón)]. Algunos sindicatos incluso se han implicado en la adquisición de participaciones en activos públicos desnacionalizados («British Rail Hotel», «National Freight Company»...). Tampoco los partidos de la oposición parlamentaria han sido capaces de impedir una política a la que se oponían (aunque la Cámara de los Lores haya modificado algunas leyes). Prácticamente no ha habido resistencia interna en las empresas elegidas para su desnacionalización: los presidentes de la industria nacionalizada (excepto Lord Kearton en BNOC) la han apoyado, y se ha garantizado la cooperación de los trabajadores, vendiéndoles acciones. Pero determinados grupos sectoriales del Estado del Bienestar han logrado impedir reducciones del gasto público y obstaculizar toda política privatizadora radical. Estos grupos incluyen sindicatos locales, funcionarios de la Administración local, funcionarios de la Administración central y los poderosos grupos profesionales (como médicos, urbanistas, contables y arquitectos), cuya influencia en el diseño de políticas públicas es cada vez mayor. El propio interés corporativo y sus preferencias ideológicas se han combinado para reforzar su voluntad de proteger el sector estatal y su ethos. También son escépticos en torno a la viabilidad de ciertos programas y, por ello, los han boicoteado (17).

Los grupos amenazados por la retirada del Estado siempre han sabido legitimar su hostilidad apelando a principios superiores. Así, la intervención pública en el mercado de la vivienda, aún importante incluso tras las reducciones de fondos al programa de vivienda pública, se justifica de varias formas: las leyes de arrendamiento, que protegen a los indefensos inquilinos contra los caseros sin escrúpulos; las subvenciones a las rentas municipales son un apoyo social a los pobres; la desgravación hipotecaria es un método de creación de una «democracia de propietarios» (uno de los objetivos reconocidos de la Administración Thatcher); las normas sobre planeamiento salvaguardan el medio ambiente.

Así pues, estos grupos pueden explotar políticamente cuestiones delicadas, haciéndolas más difíciles de abordar. Los médicos están especialmente dispuestos a valerse de la fuerza que les da su profesión y a veces hacen «ondear los sudarios» cuando se amenaza con reducciones.

(17) Ejemplos: la actitud del Tesoro frente a la dotación de fondos a las obras públicas mediante financiación privada. En 1982, la presión del Tesoro hizo abandonar el plan de financiación privada (a través de Pearls Assurance) de la construcción del Queen Elizabeth II Conference Centre frente a Westminster Abbey, y en 1984 el plan de que Tamac y sus asesores financiaran un tramo de carretera de siete millas en el Back Country fue abandonado debido a la oposición del Tesoro. Ver Financial Times, 30 de septiembre de 1986. 


\section{PRIVATTZACION: PROBLEMAS, CONTRADICCIONES Y PARADOJAS}

La política de limitación o reducción del dominio público ha descubierto algunos difíciles problemas intrínsecos, revelado contradicciones, producido efectos no buscados y destacado, al menos, una importante paradoja. Los problemas pueden ilustrarse al considerar los interrogantes que suscita el programa desnacionalizador: ¿qué vender y por qué?, ¿cuándo vender?, ¿cómo vender mejor?, ¿a qué precio?, ¿cómo controlar el monopolio privado desnacionalizado, o un cuasimonopolio, sin la «captura» de los entes reguladores por las industrias que se supone las deben controlar (experiencia frecuente en Estados Unidos)?, ¿cómo desvincularse por completo cuando la industria desnacionalizada sigue dependiendo de la política pública, cuando tiene gran importancia estratégica, o cuando se considera un emblema nacional?, ¿qué acción emprender si quiebra una de esas industrias?, ¿es más probable que los monopolios del sector privado protejan la libertad en mayor medida que los del sector público?, ¿es probable que se reduzcan los problemas directivos al privatizar actividades públicas? Las respuestas a estas preguntas plantean dificultades. Por ejemplo, la evidencia sobre la relativa eficacia de las empresas públicas y privadas es confusa (debido a lo difícil que es establecer criterios de medición de la eficacia) y conflictiva. El excelente rendimiento de empresas como British Telecom, British Gas, British Airways, British Petroleum o Amersham cuando pertenecían al sector público o tenían mayoría de capital público parece sugerir que otros factores (la estabilidad de los mercados, el grado de competitividad, la capacidad de dirección y la motivación de la mano de obra) pueden ser tan importantes, si no más, que la propiedad a efectos de eficacia. Es preciso recordar que el gobierno Thatcher ha desnacionalizado sólo empresas muy rentables, y que los gobiernos anteriores habían nacionalizado algunas grandes empresas privadas como British Leyland y Rolls Royce, que habían quebrado. La evidencia sobre la eficacia de los servicios concedidos es parcial y conflictiva. No existen pruebas concluyentes de que los servicios del Servicio Sanitario Nacional sean más caros que los del sector privado (18), y el coste-eficacia de las concesiones de las Administraciones central y local es controvertido. También se ha sugerido que, cuando los operadores de contratación privada han resultado más baratos, se ha debido a que las condiciones contractuales han reducido el nivel

(18) MAYNAR, «Privatizing the NHS», en Lloyds Bank Review, 148, abril 1983, p. 39. 
inicial, o porque han sufrido las condiciones laborales y los salarios de los trabajadores (19).

Algunas de las contradicciones del programa privatizador tienen su origen en los propios objetivos del programa. Así, uno de los problemas de gestión invocados para la desnacionalización era la inmanejable envergadura de las industrias nacionalizadas; sin embargo, los imperios de British Telecom, British Airways y British Gas siguen intactos. Otra razón aducida era la necesidad de llevar al sector los vientos de la competencia, pero con el fin de garantizar el éxito de la financiación se permitieron posiciones cuasimonopolísticas (British Telecom y British Gas) (20) y se mantuvieron prácticas contrarias al mercado (British Airways): privatización no siempre ba significado liberalización. La tercera razón era recaudar dinero, pero se vendieron activos muy rentables por debajo del valor de mercado con el fin de asegurar el éxito de las ventas, por motivos políticos, y para atraer a tantos pequeños inversores como fuera posible: The Economist señaló que el programa privatizador ha sido un «robo disfrazado de generosidad» (21).

\section{EL REPLIEGUE DEL ESTADO: HIBRIDOS Y QUANGOS}

No son menos difíciles de señalar las contradicciones entre los objetivos de los programas privatizadores y los que se persiguen en otras áreas: nacionalismo que conduce a dirigismo y una carencia en el mercado que es apátrida; un prejuicio instintivo en favor del «hombrecillo» frente al Estado y la conciencia de que la defensa de los derechos individuales (del consumidor, del sindicalista o inquilino) puede exigir intervencionismo estatal; la apelación de inspiración económica a la «liberación de la gente», pero aumentando, en nombre de la ley y el orden, las competencias de forma sin precedentes. Sería fácil continuar la lista. Pero lo esencial es que rediseñar la frontera entró lo público y lo privado es un ejercicio intrínsecamente difícil, que no debería considerarse en términos exclusivamente económicos.

La paradoja central de la política thatcherista puede expresarse simplemente: el «repliegue del Estado» exige un Estado fuerte, y muchos de los problemas del sector público han venido originados por la debilidad del Estado. Puede explicarse tal paradoja por la discrepancia

(19) ASHER, op. cit., capítulo 6. Para una perspectiva distinta ver DOMBERGER, Sh. MEA DOWCROFT y D. THOMPSON, Competitive tendering and afficiency: the case or refuse collection, Fiscal Studies, 7 (4), noviembre 1986, pp. 45-68.

(20) Véanse J. VICKERS y G. YARROw, Privatization and the Natural Monopolies, Londres, 1985; P. CURWEN, «British Telecom: has privatization delivered competition», en Economic Affairs, agosto-septiembre 1986, pp. 35-37.

(21) Economist, 22 de noviembre de 1986. 
entre la fuerza del Estado británico como decisor y su debilidad como aplicador.

En el contexto de la dualidad público-privado, vale la pena destacar dos fenómenos concretos: la acentuación del «hibridismo» industrial y el mantenimiento de la vasta red de quangos. Ambos contribuyen a enturbiar la línea entre lo público y lo privado.

El programa privatizador ha insistido continuamente en la superioridad de las fuerzas del mercado sobre el control político-administrativo. Sin embargo, para la mayoría de las grandes empresas la distinción es más jurídica que práctica.

Casi todas las empresas privadas importantes son «públicas» en cierta medida, porque están sometidas a algún grado de control político, están imbuidas de responsabilidades públicas, y configuradas por el entorno político (22). Además, es preciso reparar en que el gobierno Thatcher ha demostrado su falta de voluntad (en general, por intereses nacionales y defensa) de abrazar por completo la ética del mercado y la propiedad privada absoluta. El Estado conserva grandes participaciones en algunas industrias desnacionalizadas —una situación que suscita una serie de «complejas preguntas sin respuesta» sobre la relación entre él y estas industrias- (23). Se ha señalado que «en las definiciones al uso en otros países los híbridos desnacionalizados siguen siendo empresas públicas» (24). En la legislación no existen garantías frente a una futura intervención administrativa, ni procedimientos para definir la relación entre el gobierno y la empresa desnacionalizada. En realidad los aspectos formales (composición del Consejo, Ministerio de adscripción titular de las acciones, normas sobre posible intervención estatal) difieren de empresa a empresa. El resultado es una situación confusa e impredecible: no existe un marco común que permita una clara definición de la relación Estado-empresa desnacionalizada con participación de éste en su capital. Por tanto, en algunos aspectos la Administración Thatcher ha oscurecido la relación públicoprivado en lugar de redefinirla, y lo mismo cabe decir de los quangos, en particular, de los relacionados con el sector industrial. Acosado por presiones electorales, políticas, burocráticas y sociales, limitado por la incapacidad o el desinterés del sector privado por asumir un papel más activo, el gobierno se ha resignado a la imposibilidad de dirigir plenamente el sector público. Ha desnacionalizado y vendido viviendas municipales, pero debe gestionar y vivir con un amplio abanico de servicios públicos. Hoy, la retórica ha cambiado algo, y cada vez se pone

(22) Para un estudio excelente del tema ver B. BOzEMAN, All Organizations are Public: Bridging Public and Private Organizational Theories, Londres, 1987.

(23) D. R. STEEL, "Government and the new hybrids: a trail of unanswered questions», en Fiscal Studies, 5 (1), 1984, pp. 87-97.

(24) D. HEALD, Will the Privatization..., cit., p. 12. 
más énfasis en «tender puentes» y «cooperar» entre el sector público y el privado, pero sigue desconfiando del sector público y no ha conseguido moralizar al privado. Por tanto, la única estrategia posible es la «asociación». Pero ello implica inevitablemente una interacción creciente entre lo público y lo privado, lo que ha sido siempre un rasgo de la política social británica (25). El resultado es que, en términos políticos, el sector mixto -ese área gris e indefinida en que lo público y lo privado se entremezclan de forma frecuente y a menudo desconcertante- posiblemente ha crecido desde 1979. La distinción público-privado, tan cara al thatcherismo, ha demostrado ser en gran medida ilusoria, ya que «no hay una distinción, sino varias» (26). Podría ser mejor hablar no de una dualité, sino de lo público-privado, o hasta de un mosaique: una multitud de relaciones con frecuencia mal definidas, ambiguas y cambiantes. Esta situación se refleja en la existencia en Gran Bretaña de numerosos órganos autorreguladores (como el Consejo del Mercado de Valores y el Consejo Médico General), organizaciones voluntarias, quangos y otros agentes marginales de la política pública (27). La intención inicial del gobierno Thatcher era suprimir el mayor número posible de quangos, y de hecho, redujo su número durante los primeros cuatro años. Pero disminuyó la tasa de reducción y se han creado otros nuevos. Ello se debe a que el gobierno depende cada vez más de ellos, y el motivo nos lleva al núcleo del dilema thatcheriano: la Administración central se ha vinculado al mantenimiento de un vasto compromiso de políticas públicas, pero sus instrumentos de política directa están insuficientemente dotados para controlar o articular ese compromiso.

Gran Bretaña es un país centralizado -más, en la práctica, que Francia, el criticado modelo jacobino-. Su sistema político y administrativo es «abrumadoramente centralista», pero no es opresivo ni se percibe como tal, pues aunque es omnipresente y poderoso, también es distante y discreto. La Administración central permanece ajena al desarrollo de esas políticas: tiende a practicar una estrategia de «manos fuera». Es básicamente no ejecutiva (en contraste con la situación francesa) y ha debido dejar en general gran discrecionalidad política a los entes ejecutores -Administración local, quangos y diversas orga-

(25) L. RAINWATER y M. REIN, «Public-Private Interplay», en Social Welfare, Londres, 1984; R. Sugden, Voluntary Organizations and the Welfare State, en J. LE GRAND y RoBINSON, op. cit., pp. 70-89. Por ejemplo, L. Chalus, aRegulation in Welfare: the case of a "good home"", en Political Quarterly, vol. 53 (3), julio-septiembre 1982, pp. 329-333, y G. CARPENTER, «National Health Insurance: a case study in the use of private non-profit making organization in the provisio of welfare benefits", en Public Administration, 622 (1), Spring, 1984, pp. 71-89.

(26) J. E. LANE, «Public Policy of Makets? The demarcations Problem», en J. E. LanE, op. cit., pp. 3-52.

(27) Sir N. CHESTER, «Fringe bodies, quangos and all that», en Public Administration, vol. 57 (1), 1979. 
nizaciones voluntarias- - El gobierno Thatcher, por razones ideológicas y financieras, debilitó su propia Administración central y ha desconfiado profundamente de la Administración local. En realidad, el período Thatcher se ha caracterizado por un ataque sin precedentes contra las funciones, derechos y prerrogativas de la Administración local. $\mathrm{Su}$ dependencia de agentes no estatales ha aumentado como consecuencia de una política deliberada de evitación de los canales tradicionales. Han sobrevivido los quangos más importantes y se han creado otros nuevos: entes empresariales locales (había 162 en mayo de 1984), sociedades de desarrollo urbanístico (en Merveyvide Greater Manchester, West Midlands, Teesside y Tyne and Wear), empresas de ciudades interiores, la organización «Business in the Community» (establecida en 1982) se cuentan entre las muchas aceptaciones thatcherianas de la interdependencia de los intereses públicos y privados. Algunos entes esencialmente privados, como el Consejo Nacional de Mejora de la Vivienda (dirigido por la industria de la construcción), y organizaciones de formación de base empresarial han recibido responsabilidades y subvenciones públicas crecientes.

La dirección de este «sector mixto» suscita problemas legales, metodológicos (la mera identificación y definición de sus características no es tarea fácil), políticos (por ejemplo, la responsabilidad), administrativos (coordinación de actividades) y económicos (ya que muchos son hábiles defensores y promotores de una costosa intervención pública) (28). No obstante, la Administración Thatcher ha comprobado que los tan criticados quangos desempeñan una serie de funciones útiles: constituyen un conveniente amortiguador político entre el Estado y el consumidor (los recortes del gasto se distribuyen por agentes no estatales); son una fuente de patrocinio; ayudan a encauzar y armonizar exigencias dispares. Pero, sobre todo, se perciben como instrumentos discretos e indiscretos de la influencia estatal; agentes privados de la política pública.

En algunos supuestos se da una mayor implicación estatal (se fijan objetivos y se supervisan de cerca las actividades); pero en otros se otorga una gran discrecionalidad a algunos entes autorregulados que fijan pautas públicas y ejercen gran influencia en la política pública. La influencia puede ir desde actuaciones abiertas y lejanas, hasta actuaciones cerradas y de conspiración que asumen aquellos profesionales de intereses e ideales afines (29). Su existencia se ha considerado de dis-

(28) Para un estudio de estos temas, véanse W. Friedmann, The State and the Rule of Law in Mixed Economy, Londres, 1974; B. L. SMITH, The New Political Economy: The Public Use of the Private Sector, Londres, 1974.

(29) Para un buen debate sobre estas cuestiones véanse P. DUNLEAVY, «Quasigovernmental sector professionalism: some implications for public policy-making in Britain», en Anthony BARKER (ed.), Quangos in Britain, Londres, 1982, pp. 181-205. 
tintas formas: testimonio del fracaso del mercado y del Estado a la hora de suministrar bienes y servicios públicos; manifestación de saludable pluralismo; como muestra del neocorporativismo en que se responsabiliza parcialmente a los interesados de la aplicación de decisiones públicas. Sin embargo, todos los casos dan fe de la interpenetración de lo público y lo privado, y contribuyen a difuminar la frontera entre ambos.

\section{CONSIDERACIONES FINALES}

Extraeremos, por último, una serie de conclusiones generales a partir de los intentos del gobierno Thatcher de redefinir los límites entre lo público y lo privado mediante una política privatizadora:

- El gobierno sigue comprometido con determinados objetivos de esa política, y está decidido a aplicarlos: desnacionalización, contratación externa, ventas de viviendas municipales, introducción de prácticas privadas en los servicios del sector público.

- Los intentos de alterar radicalmente el equilibrio público-privado han fracasado ante la inercia burocrática, la resistencia política, las inadecuaciones del mercado y las grandes dificultades de algunos de los problemas planteados. Los elementos públicos siguen predominando abrumadoramente en la mayoría de los servicios sociales.

- El gobierno se ha mostrado remiso a seguir la lógica de su propia retórica de mercado; ha conservado participaciones en empresas desnacionalizadas, y continúa siendo dirigista en la adopción de decisiones industriales y económicas.

- Se ha logrado reducir el sector público a través de las concesiones y de la desnacionalización, y se ha logrado su sensibilización en el ethos del sector privado.

- En ciertas áreas ha aumentado el intervencionismo estatal (competencias policiales, educación, formación industrial, protección del consumidor, legislación sindical) o se ha hecho más selectivo y específico (política regional).

La política thatcherista de «repliegue del Estado» ha ido acompañada de contradicciones y consecuencias no pretendidas. El programa privatizador no ha resuelto muchos de los problemas que pretendía solucionar, como los de competitividad a través de la liberalización y los de eficacia a través de las reformas de las estructuras organizativas y directivas.

- En lo que se refiere a la adopción de decisiones, se ha producido una creciente centralización (con motivo de los ataques a la Administración local) y complejización de aquéllas, con motivo de la pro- 
liferación de entes público-privados (con fórmulas de relaciones internas muy diversas) y de grupos industriales híbridos.

- La dicotomía público-privado es falsa: ambos forman un entramado permanente y complejo que integra un vasto «sector mixto» de competencias y límites indeterminados.

El gobierno Thatcher se hace falsas ilusiones al creer que puede reducir los límites del dominio público de forma significativa: exigencias de soberanía nacional, defensa, armonía social, equilibrio regional, presiones de grupos profesionales, prudencia electoral y autoengrandecimiento burocrático hacen inevitable una influencia pública permanente y extensa - directa o indirecta - en la producción y distribución de bienes colectivos. Debe recordarse que el crecimiento del sector público no fue fruto de una ideología malévola encaminada a acabar con la libertad privada, sino antes bien una consecuencia del fracaso del mercado en la satisfacción de aspiraciones colectivas e individuales y en la protección y extensión de las libertades privadas.

La cuestión no es, pues, optar entre lo público y lo privado, sino combinarlos adecuadamente, planteándose en el momento de la asignación de recursos la pregunta de qué es lo que corresponde al mercado y qué es lo que pertenece al sector público. En todo caso lo público y lo privado están condenados a convivir juntos y el desafío está en la conducción de ese proceso de coexistencia. Negar al ámbito público su legitimidad conduce a su desmoralización (caso de muchos servicios públicos en Gran Bretaña) sin que necesariamente se mejore por ello la productividad del sector privado.

Traducción: Diego Agustín Carrasco Pradas 


\section{DA-1989, núms. 218-219. VINCENT WRIGHT. Las privatizaciones en Gran Bretaña}

DA-1989, núms. 218-219. VINCENT WRIGHT. Las privatizaciones en Gran Bretaña 